\title{
FROM RAW TO FINISHED COTTON-CHARACTERIZATION BY INTERFACE PHENOMENA
}

\author{
Ana Marija GRANCARIĆ ${ }^{1}$, Anita TARBUK ${ }^{1}$, Samira HADŽIĆ ${ }^{2}$, and Barbara SIMONČIČ ${ }^{2}$ \\ 1 University of Zagreb Faculty of Textile Technology, Department of Textile Chemistry and Ecology, Prilaz baruna Filipovića 28a, 10000 Zagreb, CROATIA \\ 2 University of Ljubljana, Faculty of Natural Sciences and Engineering, Department of Textiles, Aškerčeva 12, 1000 Ljubljana, SLOVENIA \\ Corresponding Author. E-mail: amgranca@ttf.hr, anita.tarbuk@ttf.hr
}

\begin{abstract}
:
Interface phenomena that occur at the solid-liquid interface, such as wettability, adsorption, and particle aggregation, depend on the kind and magnitude of the solid surface free energy and electrokinetic properties found in water solutions. These phenomena are crucial for textile dyeing, finishing, and care. They characterize the material surface and change with different material pretreatment and finishing. In this paper, electrokinetic potential, isoelectric point, point of zero charge, a specific amount of surface charge and surface free energy of raw, enzymatically scoured, bleached, and finished cotton fabrics were investigated. Electrokinetic potential was measured by a streaming potential method and a specific quantity of surface charge by the back-titration method. For determination of the solid surface free energy components, the thin-layer wicking and contact-angle methods were used. On the basis of these results, components of solid surface free energy were calculated and discussed.
\end{abstract}

\section{Keywords:}

cotton fabric, scouring, bleaching, DMDHEU, FC resin, zeta potential (ZP), surface charge, surface free energy

\section{Introduction}

The most important phases in the textile finishing are adsorption and wettability of textile material. These phenomena occur at the solid-liquid interface, such as textile material and water solutions. Interface phenomena significantly depend on the solid surface free energy and surface electrokinetic properties in water solutions, such as zeta potential (ZP) and a specific amount of surface charge [1-20]. At the interface of electrically charged textile fibers and an aqueous solution of electrolyte, surfactants or dyes, an electric double layer is set up, inducing the electrokinetic potential (ZP). Most of textile fibers show the negative values of the $\mathrm{ZP}$ when immersed in water $(\mathrm{pH}$ 6.5-7.0). The isoelectric point (IEP) is a numeric value of $\mathrm{pH}$ where electrokinetic potential equals zero. The point of zero charge (PZC) represents the necessary amount of surfactant of opposite charge added to the electrolyte solution to achieve zero charge at a constant $\mathrm{pH}(\mathrm{pH}>9)$. The $\mathrm{ZP}$ gives information about nature and dissociation of functional groups, hydrophilicity, or hydrophobicity of the fiber surface as well as ions or water sorption and the portion of amorphous regions where the adsorption processes take place [2-5, 8-12]. In general, specific adsorption of ions or dissociation of the surface groups in aqueous solution results with their surface charge, which depends on their molecular and supramolecular structure, swelling capacity, ionogenity, structure, and concentration of adsorbate [5, 13]. These phenomena are crucial for textile dyeing and finishing as well as for textile care.
Changing the number of functional fiber surface groups, for example, by blocking in dyeing and finishing processes, and their dissociation affect the distribution of the surface charge, surface free energy, and the thickness and distribution of the electric double layer, resulting in different fabric interface phenomena [3-20]. When a drop of liquid is set on a solid surface, it creates a contact angle. By researching the contact angles that different liquids form on textile material, its wettability and surface free energy can be characterized $[6,16-$ 26]. Therefore, the contact angle methods to determine surface free energy of cotton raw, scoured, bleached, and finished cotton fabrics according to the Fowkes, Owens-Wendt, and Wu model were performed. Since textiles are heterogeneous, porous, and mostly hydrophilic material, surface free energy is complicated and sometimes impossible to determine by the contact-angle method $[6,7,27,28]$. Therefore, in this paper, the Chibowski thin-layer wicking method for the textile surface free energy components determination was performed and compared to contact-angle methods.

\section{EXPERIMENTAL}

In this paper, the ZP, IEP, and PZC with $\mathrm{N}$-cetylpyridinium chloride, specific amount of surface charge and surface free energy of raw, bio-scoured, bleached, and finished cotton fabrics were investigated to characterize the cotton fabric surface. 


\subsection{Material}

A plain weave fabric of $100 \%$ cotton and of surface mass 150 $\mathrm{g} / \mathrm{m}^{2}$ was used (sample R). Fabric was desized for $3 \mathrm{~h}$ at $60^{\circ} \mathrm{C}$ in an autoclave (Scholl) by a pad roll using $3 \mathrm{~g} / \mathrm{l}$ of amilase Beisol LZV (Bezema) and $2 \mathrm{~g} / \mathrm{l}$ of wetting agent Kemonetzer $\mathrm{NI}\left(\right.$ Kemo). It was bio-scoured for $3 \mathrm{~h}$ at $60^{\circ} \mathrm{C}$ in an autoclave (Scholl) by a pad roll using $3 \mathrm{~g} / \mathrm{l}$ of pectinase Beisol PRO (Bezema) and $1 \mathrm{~g} / \mathrm{l}$ of wetting agent Felosan NOG (Bezema) (sample ES). After enzymatic scouring, the fabric was bleached with hydrogen peroxide (HP) in a laboratory for $3 \mathrm{~h}$ at $98^{\circ} \mathrm{C}$ in an autoclave (Scholl) by a pad roll using $20 \mathrm{ml} / / \mathrm{l}$ of $\mathrm{H}_{2} \mathrm{O}_{2}(35 \%), 4 \mathrm{~g} / \mathrm{l}$ $\mathrm{NaOH}, 5 \mathrm{ml} / / \mathrm{T}$ Tinoclarit CBB (Ciba), $15 \mathrm{ml} / /$ of mixture $\mathrm{Na}_{2} \mathrm{SiO}_{3}$, $\mathrm{Na}_{2} \mathrm{Si}_{2} \mathrm{O}_{5}, 10 \mathrm{ml} / \mathrm{I}$ Invatex MD (Ciba), and $0.5 \mathrm{ml} / \mathrm{l}$ Fumexol DF (Ciba) (sample EB). Under industrial conditions, the fabric was alkaline scoured for $1 \mathrm{~h}$ at $95^{\circ} \mathrm{C}$ in a bath containing $0.5 \mathrm{~g} / \mathrm{l}$ of nonionic wetting agent Kemonetzer $\mathrm{NI}$ and $5 \mathrm{ml} / \mathrm{I} \mathrm{NaOH} \mathrm{(48 \% ),}$ and $\mathrm{HP}$ bleached for $1 \mathrm{~h}$ at $90^{\circ} \mathrm{C}$ in peroxide baths containing $1 \mathrm{~g} / \mathrm{l}$ of nonionic wetting agent Lavotan TBU (Bezema), $1 \mathrm{~g} / \mathrm{L}$ of Stabilizator DP (Kemo), $2 \mathrm{ml} / / \mathrm{NaOH}(48 \%)$, and $5 \mathrm{ml} / / \mathrm{H}_{2} \mathrm{O}_{2}$ (35\%) (sample B).

HP-bleached cotton fabric (Sample B) was then finished (F 1 $-F 3$ ) by the pad-dry-cure procedure. Padding was performed twice on foulard (Mathis), with wet pick up $\mathrm{Wp} \approx 85 \%$ at $\mathrm{pH} 4$. The padding bath for water- and oil-repellent finish (sample $\mathrm{F}$ 1) contained: $60 \mathrm{~g} / \mathrm{l}$ Tubicoat HP 27 (CHT) - fluorocarbon (FC) resin; $15 \mathrm{~g} / \mathrm{l}$ isopropanol (Sigma Aldrich), $25 \mathrm{~g} / \mathrm{l}$ Tubicoat HPE conc. (CHT) - extender based on modified melamine resin free from metallic salts; $1 \mathrm{~g} / \mathrm{l} 60 \% \mathrm{CH}_{3} \mathrm{COOH}$. The bath for easy-care finish (sample F 2) contained $80 \mathrm{~g} / \mathrm{l}$ Reaknitt B-FF $(\mathrm{CHT})$ - crosslinking agent based on modified di-methylol-dihydroxy-ethylene urea (DMDHEU); $10 \mathrm{~g} / \mathrm{l}$ Tubingal SKI (CHT) silicone containing fatty acid condensation product with special additives, a pseudocationic, multifunctional softener; $15 \mathrm{~g} / \mathrm{l}$ $\mathrm{MgCl}_{2} \times 6 \mathrm{H}_{2} \mathrm{O}$. The bath for multifunctional finishing (Waterand oil-repellent + easy-care finish) (sample $\mathrm{F} 3$ ) contained $25 \mathrm{~g} / \mathrm{I}$ Tubicoat HPE conc. (CHT), $15 \mathrm{~g} / \mathrm{l}$ isopropanol (Sigma Aldrich), $60 \mathrm{~g} / \mathrm{l} \mathrm{Tubicoat} \mathrm{HP} 27$ (CHT); $1 \mathrm{~g} / \mathrm{l} 60 \% \mathrm{CH}_{3} \mathrm{COOH}$; $80 \mathrm{~g} / \mathrm{l}$ Reaknitt B-FF (CHT); $10 \mathrm{~g} / \mathrm{l}$ Tubingal SKI (CHT); $15 \mathrm{~g} / \mathrm{l}$ $\mathrm{MgCl}_{2} \times 6 \mathrm{H}_{2} \mathrm{O}$. The impregnated fabrics were dried at $100^{\circ} \mathrm{C}$ for

Table 1: Labels and treatments of cotton fabrics

\begin{tabular}{|c|c|}
\hline Fabric & Treatment of cotton fabric \\
\hline $\mathrm{R}$ & Raw \\
\hline ES & Bio-scoured under laboratory conditions \\
\hline EB & $\begin{array}{l}\text { Bio-scoured and HP bleached under } \\
\text { laboratory conditions }\end{array}$ \\
\hline B & $\begin{array}{c}\text { Alkaline scoured and HP bleached under } \\
\text { industrial conditions }\end{array}$ \\
\hline F 1 & Water- and oil-repellent finish (FC resin) \\
\hline F 2 & Easy-care finish (DMDHEU) \\
\hline F 3 & Water- and oil-repellent + easy-care finish \\
\hline
\end{tabular}

$3 \mathrm{~min}$ and cured at $150^{\circ} \mathrm{C}$ for $2 \mathrm{~min}$. The labels and treatments are listed in Table 1.

\subsection{Methods}

The characterization of surface and chemical composition of cotton fabrics were performed applying instrumental methods: Fourier transform infrared-attenuated total reflectance (FTIRATR) spectroscopy, and electrokinetic analysis (EKA). For these purposes, all the fabrics were rinsed to the conductivity of deionized water $(2-4 \mu \mathrm{S} / \mathrm{cm})$.

The cotton fabrics were analyzed by FTIR spectrometer (PerkinElmer, software Spectrum 100). Sixteen scans at a resolution of $4 \mathrm{~cm}^{-1}$ were recorded for each sample between 4000 and $400 \mathrm{~cm}^{-1}$.

Electrokinetic (zeta, $\xi$, ZP) potential was measured by streaming potential/current method using the BrookhavenPaar Electrokinetic Analyzer with a stamp cell and calculated according to the Helmholtz-Smoluchowsky equation [4]. It was investigated versus $\mathrm{pH}$ and versus cationic surfactant addition. The IEP of textile fabrics was determined as well as the PZC. In this work, PZC was determined using $\mathrm{N}$-cetylpyridinium chloride (N-CPC).

Specific quantity of surface charge was calculated after the back-titration method [5] applying the Titrino 736 (Metrohm) and ionic surfactant electrode 6.0507.120 (Metrohm). N-CPC was used as cationic, and sodium dodecyl sulfate (NDDS) as anionic surfactant polyelectrolyte solution. For the calculation, at least five fabric samples dwelt in the solution, and at least 10 titrations were performed.

The surface free energy of solid substances $\left(\mathrm{Y}_{\mathrm{s}}\right)$, according the approach of van Oss et al. [24, 25] considering the surface free energy as the sum of nonpolar Lifshitz-van der Waals $\left(\mathrm{Y}^{\mathrm{LW}}\right)$ and polar acid-base $\left(\mathrm{\gamma}^{\mathrm{AB}}\right)$ interactions:

$\gamma_{S}=\gamma_{S}{ }^{L W}+\gamma_{S}{ }^{A B}$

For the interactions between solid $S$ and liquid $L$, it may be written as

$\Delta G_{S L}=\Delta G_{S L}^{L W}+\Delta G_{S L}^{A B}$

Where $\Delta G_{S L}{ }^{L W}$ is the free energy change due to Lifshitz-van der Waals interactions and $\Delta \mathrm{G}_{\mathrm{SL}}{ }^{\mathrm{AB}}$ is due to acid-base interactions.

$\Delta G_{S L}=-2 \sqrt{\gamma_{S}^{L W} \gamma_{L}^{L W}}-2 \sqrt{\gamma_{S}^{+} \gamma_{L}^{-}}-2 \sqrt{\gamma_{S}^{-} \gamma_{L}^{+}}$

Young-Dupre showed that

$\gamma_{L}(1+\cos \theta)=2\left(\sqrt{\gamma_{S}{ }^{L W} \gamma_{L}{ }^{L W}}+\sqrt{\gamma_{S}{ }^{+} \gamma_{L}{ }^{-}}+\sqrt{{\gamma_{S}}^{-} \gamma_{L}{ }^{+}}\right)$

which is known as van Oss-Chaudhury-Good (OCG) thermodynamic approach to determine the values of surface free energy components of solids, that is, $\mathrm{Y}_{S}{ }^{L W}, \mathrm{Y}_{S}{ }^{-}$, and $\mathrm{Y}_{S}{ }^{+}$. To determine these values, it is necessary to determine contact 
angles of three different liquids of known properties $\left(\mathrm{Y}_{L}{ }^{L W}, \mathrm{Y}_{L}{ }^{-}\right.$, and $\mathrm{Y}_{L}^{+}$).

Textiles are heterogeneous, porous, and mostly hydrophilic; therefore, sometimes, it is impossible to measure SFE by the contact angle method-in the case that the solid surface is not sufficiently hydrophobic that the liquid droplet stays and forms an angle on the surface. In that case, the thin-layer wicking can be used [6]. For that reason, both the contactangle method and thin-layer wicking method were applied for determination of SFE components.

The static (equilibrium) contact angles of sessile drops of liquids on all fabrics were measured as a function of time [18] on the FIBRO DAT 500/1100 (Fibro) instrument using three different liquids—distilled water, formamide (p.a. 99.5 $\%$, Fluka), and diiodomethane (p.a. $99 \%$, Aldrich)—at $23^{\circ} \mathrm{C}$. From the image of the drop on the surface, using the Young-Laplace fitting the contact angle was determined. The complete drop contour was evaluated, taking into account the drop deformation caused by liquid weight, which, besides interfacial effects, also contributed to the drop shape. Liquid drops of $4 \mu \mathrm{l}$ were deposited on different spots of the cotton fabrics to avoid the influence on the drop shape due to gravity and fabric roughness and heterogeneity. The average values of contact angles in 30-60 s from the deposition of the drops were calculated from at least ten measurements on each of the studied fabrics at $20^{\circ} \mathrm{C}$ and the ambient humidity. From the results of contact-angle measurement, the disperse Lifshitzvan der Waals $\left(\mathrm{Y}^{\mathrm{LW}}\right)$ and polar acid-base $\left(\mathrm{Y}^{\mathrm{AB}}\right)$ interactions and components of surface free energies $\left(Y_{L}{ }^{\text {TOT }}, Y_{L}{ }^{-}\right.$and $\left.Y_{L}{ }^{+}\right)$were calculated by using the following models:

ACID-BASE Fowkes's model [21] is based on the assumption that the phases that are in contact could behave as electron donors and/or electron acceptors, that is, the surface energy (Yi) and interfacial energy (Yij) are expressed as follows:

$$
\begin{aligned}
& \gamma_{i}=\gamma_{i}^{L W}+\gamma_{i}^{a b} \\
& \gamma_{i j}=\gamma_{i j}^{L W}+\gamma_{i j}^{a b} \\
& \gamma_{i j}^{L W}=\gamma_{i}^{L W}+\gamma_{j}^{L W}-2 \sqrt{\gamma_{i}^{L W} \gamma_{j}^{L W}}=\left(\sqrt{\gamma_{i}^{L W}}-\sqrt{\gamma_{j}^{L W}}\right)^{2} \\
& \gamma_{i j}^{a b}=2\left(\sqrt{\gamma_{i}^{+}}-\sqrt{\gamma_{j}^{+}}\right)\left(\sqrt{\gamma_{i}^{-}}-\sqrt{\gamma_{j}^{-}}\right)
\end{aligned}
$$

\section{OWENS-WENDT's model}

This is one of the most common methods for calculating the SFE of polymeric materials, while water and diiodomethane are being used most frequently as the measuring liquids [24]

$\gamma_{i j}=\gamma_{i}+\gamma_{j}-2\left(\gamma_{i}^{d} \gamma_{j}^{d}\right)^{1 / 2}-2\left(\gamma_{i}^{p} \gamma_{j}^{p}\right)^{1 / 2}$

where the whole surface energy is a sum of dispersed $(d)$ and polar $(p)$, components, that is,

$\gamma=\gamma^{d}+\gamma^{p}$ interfacial free energy ( $v i j)$ is expressed by geometric mean of the surface energies of two phases that are in contact.

\section{WU's model}

$\gamma_{i j}=\gamma_{i}+\gamma_{j}-\frac{4 \gamma_{i}^{d} \gamma_{j}^{d}}{\gamma_{i}^{d}+\gamma_{j}^{d}}+\frac{4 \gamma_{i}^{p} \gamma_{j}^{p}}{\gamma_{i}^{p}+\gamma_{j}^{p}}$

where the whole surface energy of a phase as a sum of dispersed $(d)$ and polar $(p)$ components; interfacial free energy $(\gamma i j)$ is expressed by the harmonic mean of the surface energies of two phases that are in contact [25].

All these models are adequate if the solid surface is sufficiently hydrophobic that liquid droplets will stay on the surface forming an angle- "contact angle." Textiles are heterogeneous, porous, and mostly hydrophilic; therefore, surface free energy is complicated, and sometimes it is impossible to measure by the contact-angle method [6].

For the determination of the textile surface free energy components in accordance to thin-layer wicking proposed by Chibowski et al. [27, 28], the rate of the liquid penetration (wicking) into the porous solid can be described with the general form of the Washburn equation for the horizontal capillary. If the wicking experiments are carried out in four wicking systems, four different values of the free energy change occurs, and work of adhesion $\left(\mathrm{W}_{\mathrm{A}}\right)$ can be calculated from the results of the liquid penetration rates using the van Oss approach:

$W_{A}=2 \sqrt{\gamma_{S}^{L W} \gamma_{L}^{L W}}+2 \sqrt{\gamma_{S}^{+} \gamma_{L}^{-}}+2 \sqrt{\gamma_{S}^{-} \gamma_{L}^{+}}$

from which nonpolar Lifshitz-van der Waals, $V_{S}{ }_{S}$; ; polar electron donor, $V_{s}$; and electron acceptor, $V_{S}{ }^{+}$, components of the solid surface free energy can be calculated, if the components $V_{L}{ }^{L W}$, $V_{L}{ }_{L}$, and $V_{L}^{+}$of the liquids are known. In order to determine the solid surface free energy components, at least three liquids, one nonpolar completely spreading liquid and two polar liquids, should be used for wicking.

For the thin-layer wicking experiments, n-heptane as a nonpolar completely spreading liquid, and water and formamide as polar noncompletely wetting liquids, were used. Experiments were carried out in the same way as recommended by Grancarić et al. [7]. For every fabric sample, 10 measurements were made at $20 \pm 1^{\circ} \mathrm{C}$. From a wicking distance of polar and nonpolar solvents, components of the surface free energy were calculated.

\section{RESULTS}

The changes in the structure and chemical composition of the cotton fabrics were investigated by FTIR-ATR spectroscopy on a Spectrum GX FT-IR (Perkin-Elmer). The results are shown in Figure 1.

Some characteristic bands related to the physical and chemical changes can be seen from Figure 1-the hydrogen-bonded $\mathrm{OH}$ at $4000-2995 \mathrm{~cm}^{-1}$ (the intramolecular hydrogen bonding of $\mathrm{O} 2-\mathrm{H}---\mathrm{O} 6$ and $\mathrm{O} 3-\mathrm{H}---\mathrm{O} 5$, and the intermolecular hydrogen 


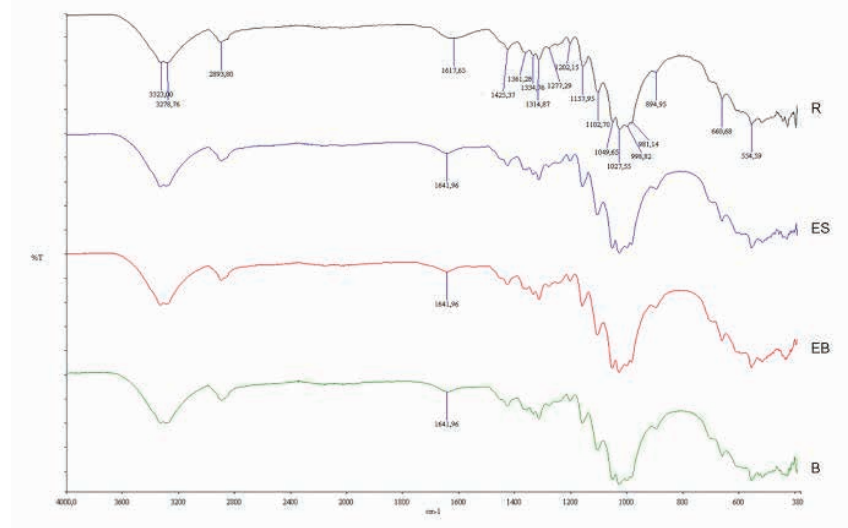

a.

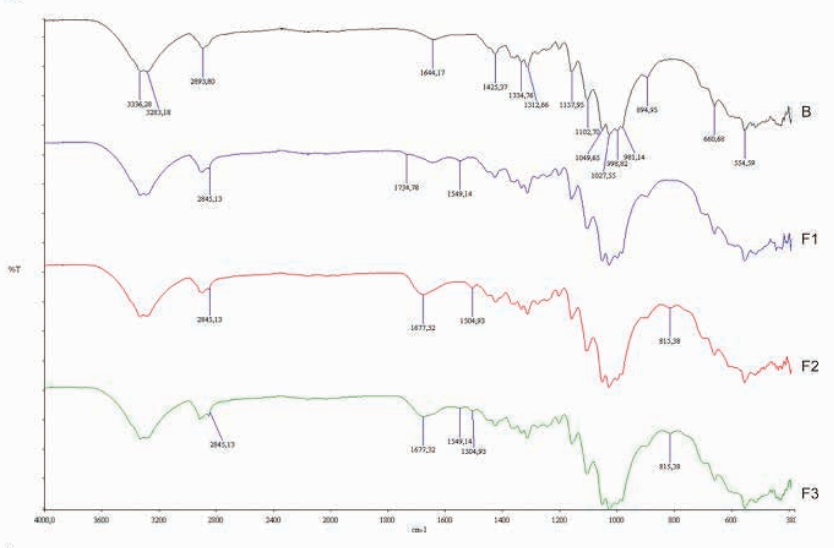

b.

Figure 1 ATR FT-IR spectra of cotton fabrics - a. pretreated (R - raw; ES - enzymatic scoured; EB - enzymatic scoured and HP bleached; B - HP bleached); b. finished (F 1 - Water- and oil-repellent finish, $F$ 2 - Easy-care finish; F 3 - Water- and oil-repellent + easy-care finish)

bonding of $\mathrm{O} 6-\mathrm{H}---\mathrm{O} 3$ in cellulose are generally shown at $3455-3410$, 3375-3340, and 3310-3230 $\left.\mathrm{cm}^{-1}\right)$; $\mathrm{OH}$ bending of adsorbed water $\left(1615-1645 \mathrm{~cm}^{-1}\right)$; the $\mathrm{CH}$ stretching at $2900 \mathrm{~cm}^{-1}$ (overlapping of the stretch asymmetric vibrations of -CH2- generally around $2935-2915 \mathrm{~cm} \mathrm{~cm}^{-1}$ and $-\mathrm{CH} 3$ around $2970-2950 \mathrm{~cm}^{-1}$, and by the overlapping of stretch symmetric vibrations of $-\mathrm{CH} 2$ - around $2865-2845 \mathrm{~cm}^{-1}$ and $-\mathrm{CH} 3$ around $2880-2860 \mathrm{~cm}^{-1}$ ); the $\mathrm{HCH}$ and $\mathrm{OCH}$ in-plane bending vibrations at $1425 \mathrm{~cm}^{-1}$, the $\mathrm{CH}$ deformation vibration at $1335 \mathrm{~cm}^{-1}, 1155 \mathrm{~cm}^{-1} \mathrm{C}-\mathrm{C}$ asymmetric bonds; $1105 \mathrm{~cm}^{-1}$ $\mathrm{C}-\mathrm{O}-\mathrm{C}$ bridges, glycoside bonds; $1050 \mathrm{~cm}^{-1} \mathrm{C}-\mathrm{OH}$ secondary alcohols; $1025 \mathrm{~cm}^{-1} \mathrm{C}-\mathrm{OH}$ primary alcohols; $1005 \mathrm{~cm}^{-1}$ and 985 $\mathrm{cm}^{-1}-\mathrm{CH}-$ bonds; and the $\mathrm{COC}, \mathrm{CCO}$, and $\mathrm{CCH}$ deformation modes and stretching vibrations in which the motions of the C-5 and C-6 atoms are at $895 \mathrm{~cm}^{-1}$ and the $\mathrm{C}-\mathrm{OH}$ out-of-plane bending mode at $660 \mathrm{~cm}^{-1}[15,20,29]$.

The ATR spectra revealed spectral changes in the fingerprint area $1800-500 \mathrm{~cm}^{-1}$. The characteristic band of the $\mathrm{HOH}$ bending vibrations of adsorbed water molecules occurred in the spectrum of untreated raw (Sample R) and pretreated (Samples ES, EB, and B) cellulose. Removal of the noncellulosic impurities of pectins, oils, waxes, proteins, carbohydrates, and inorganic materials from raw cotton fibers resulted in the shift of the band at $1617 \mathrm{~cm}^{-1}$ to $1642 \mathrm{~cm}^{-1}$ with a significant difference in the intensity, what suggests higher absorptivity of pretreated cotton.

For the finished cellulose, rather weak but characteristic bands appeared at 2845, 1735, 1677, 1550, 1505, 1245, and $815 \mathrm{~cm}^{-1}$. The intense symmetric and asymmetric stretching vibrations of the $\mathrm{CH}_{2}$ groups are observed at 2894 and 2845 $\mathrm{cm}^{-1}$, respectively. It is most probable that these $\mathrm{CH}_{2}$ groups form part of the backbone of the polymer and that the carbonyl group is part of an ester linkage connecting polymer chains to the backbone [30]. For the cellulose finished with FC resin (Samples F1 and F3), the most intense bands in this spectrum are observed at 1735,1550 , and $1245 \mathrm{~cm}^{-1}$. The band at $1735 \mathrm{~cm}^{-1}$ represents the carbonyl $\mathrm{C}=\mathrm{O}$ group. The band at $1245 \mathrm{~cm}^{-1}$ can be assigned to the CF2 and CF3 symmetric and asymmetric stretching vibration [30], which was expected since the finishing agent contained FC resin. However, it is interesting that the peak of $-\mathrm{C}=\mathrm{N}$ ring vibration was observed at $1550 \mathrm{~cm}^{-1}$. It can be attributed to the melamine used as an extender [31]. These peaks confirmed that the resin agent has been successfully bonded to the cellulose. For the cellulose finished with DMDHEU, the bands appeared at 1677, 1505, 1235 , and $815 \mathrm{~cm}^{-1}$. The band at $1641 \mathrm{~cm}^{-1}$, characteristic of the adsorbed water molecules, is much weaker, and completely overlapped by urea $\left(1677 \mathrm{~cm}^{-1}\right)$ in the spectra of DMDHEU finished cellulose. A strong band at $1505 \mathrm{~cm}^{-1}$ can be attributed to aromatic-, while the band at $1235 \mathrm{~cm}^{-1} \mathrm{C}-\mathrm{O}-$ can be attributed to stretch vibration. Furthermore, the IR spectra of DMDHEU-treated cellulose showed a significant difference in the intensity and the shape of the band at $900 \mathrm{~cm}^{-1}$, which is very sensitive to conformational changes of the interglucosidal bond [20]. The new peak at $815 \mathrm{~cm}^{-1}$ appeared, proving the presence of crosslinking between DMDHEU and cellulose macromolecules.

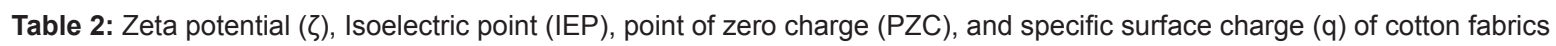

\begin{tabular}{|c|c|c|c|c|}
\hline Fabric & $\begin{array}{c}\text { Jat pH 10 } \\
{[\mathrm{mV}]}\end{array}$ & $\begin{array}{c}\text { IEP } \\
{[\mathbf{p H}]}\end{array}$ & $\begin{array}{c}\text { PZC } \\
{[\mu \mathrm{g} / \mathrm{ml}]}\end{array}$ \\
\hline R & -12.2 & $<2.5$ & 74.45 & $\mathbf{q}$ [C/g] \\
\hline ES & -13.4 & $<2.5$ & 57.86 & -2.45 \\
\hline EB & -14.9 & $<2.5$ & 56.51 & -2.36 \\
\hline B & -14.0 & $<2.5$ & 54.81 & -2.29 \\
\hline F 1 & -25.2 & 4.63 & 44.10 & -2.05 \\
\hline F 2 & -23.9 & 2.98 & 56.71 & -2.25 \\
\hline F 3 & -21.3 & 4.68 & 45.67 & -1.98 \\
\hline
\end{tabular}




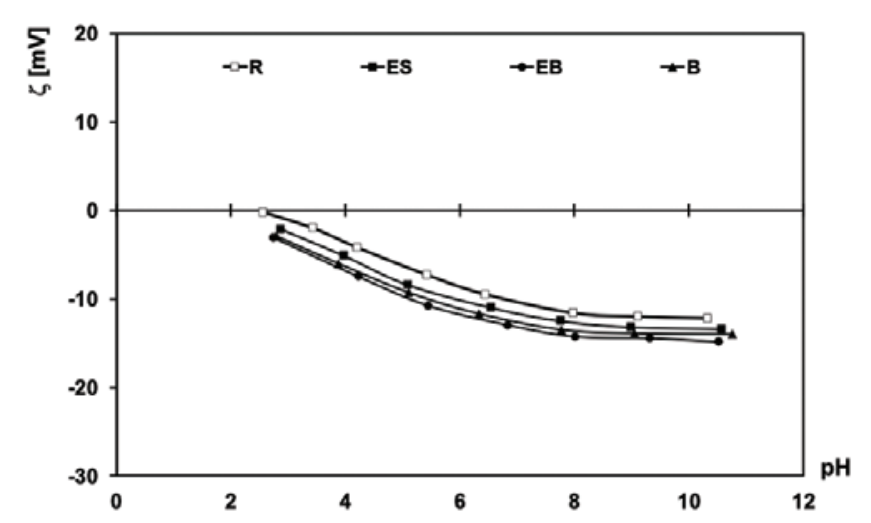

a.

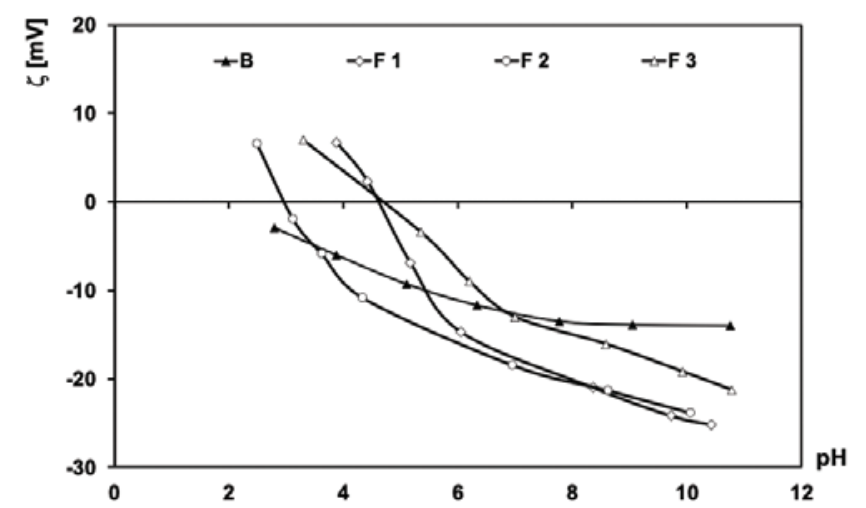

b.

Figure 2: Zeta potential ( $\zeta$ ) of the (a) pretreated and (b) finished cotton fabrics vs. the $\mathrm{pH}$ of $0.001 \mathrm{M} \mathrm{KCl}$

The ZP of the cotton fabrics was measured using EKA depending on the $\mathrm{pH}$ of the electrolyte solution and cationic surfactant N-CPC addition. The results are given in Figures 2 and3 and Table 2.

It can be seen from Table 2 and Figures 2 and 3 that all studied fabrics are negatively charged, mostly due to the presence of carboxyl and hydroxyl groups. In the case of raw cotton, hydroxyl and carboxyl groups existed, but they were covered by noncellulose compounds. Therefore, raw cotton has the ZP of $-12.2 \mathrm{mV}$. The scouring process results in degradation and removal of practically all noncellulose compounds except waxes, which remain to about $50 \%$ on the fiber. It causes interfibrillar swelling, and the active surface is increased, but the number of dissociable groups stays the same. Therefore, the $\mathrm{ZP}$ changes from $-12.2 \mathrm{mV}$ to $-13.4 \mathrm{mV}$. The oxidation in the bleaching process causes the formation of new surface groups $(-\mathrm{CO},-\mathrm{CHO}$ and $-\mathrm{COOH})$ and a second step of hydrolyzation of material, which is observed by the decreased ZP $[3,4,11,12$, 14]. The ZP of fibers decreases with the swelling and increases the absorption of water. It is assumed that swelling processes expand the inner surface of the fibers, and the shear plane of the electrochemical double layer is shifted of the shear plane into the liquid phase, for example, this swelling layer. The ZP decreases within this layer, which explains the kinetics of the swelling process. On the other hand, the composition of the electrochemical double layer is influenced by the adsorption of electrolyte ions. Because of the competitive adsorption of water molecules, the amount of adsorbed potential-determining ions
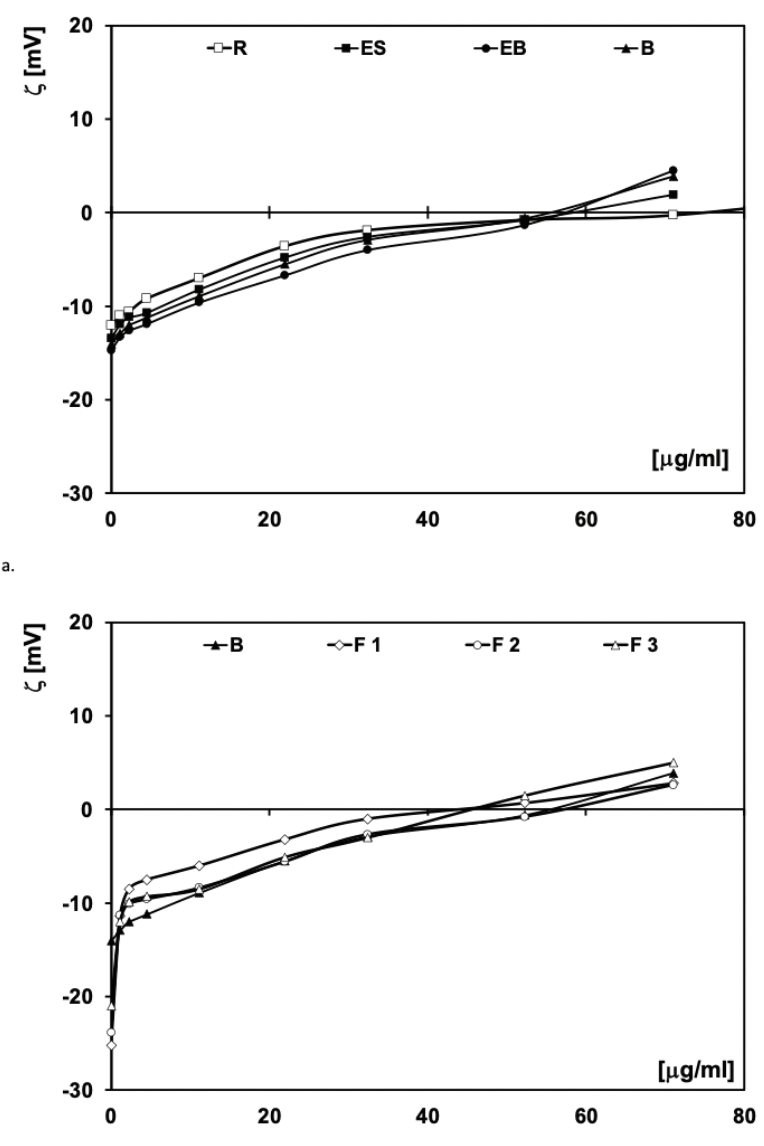

Figure 3: Zeta potential ( $\zeta$ ) of the (a) pretreated and (b) finished cotton fabrics vs. the addition of $\mathrm{N}-\mathrm{CPC}$ in $0.001 \mathrm{M} \mathrm{KCl}$ at $\mathrm{pH} 10$

decreases during the swelling process, thereby, amplifying its effect on the ZP. For all those reasons, bleached fabric $\mathrm{B}_{\text {lab }}(\zeta=-14.9 \mathrm{mV})$ has a lower ZP than $B_{\text {ind }}(\zeta=-14.0 \mathrm{mV})$, which indicates a larger number of accessible surface groups. Finishing the treatment leads to further lowering of the ZP. Applying DMDHEU (Figure 2), melamine, and FC resin (Figure 3 ) on the surface of cotton fabrics overshadows the functional hydroxyl groups of cellulose fibers with their own. Additionally, as the FTIR-ATR results showed, the DMDHEU monomers penetrated into amorphous regions of the fibers and formed covalent bonds with the hydroxyl groups of cellulose macromolecules. This led to an increased rearrangement of the amorphous regions of fibers that hindered the penetration of liquids.

Besides $\mathrm{ZP}$ at $\mathrm{pH} 10$, it is important to know the IEP and PZC. For the determination of these points, it was necessary to measure the change in ZP in dependence on the electrolyte $\mathrm{pH}$ and ionic surfactants addition. IEP is an important parameter in the dyeing and finishing. Obtained results presented in Table 3 and in Fig. 2 indicate that raw cotton fabric has an IEP in the area of less than $\mathrm{pH} 2.5$. The exact value was impossible when determining the presence of several ionic groups within the measuring system [5]. The IEPs are shifted toward lower $\mathrm{pH}$ values during the cleaning process, due to the increased accessibility of dissociable surface groups (IEP shifted from $\mathrm{pH} 2.3$ to $\mathrm{pH}$ approximately 2). In the finishing processes, change on the surface occurs, shifting the IEP to higher $\mathrm{pH}$ values. Application of DMDHEU results in an IEP of 2.98 for $F$ 
2. Treatment with $F C$ resin results in an IEP $>4.5$ regardless if applied alone (F 1) or in the bath with DMDHEU (F 3).

$\mathrm{PZC}$ was determined at $\mathrm{pH} 10$ because in that $\mathrm{pH}$ area the $\mathrm{ZP}$ has the highest and constant value. The results presented in Table 2 and in Fig. 5 showed similar behavior as the $\mathrm{pH}$ functions. Due to the noncellulose compounds that cover raw cotton fibers, it adsorbs the highest number of cationic surfactants for reaching zero-charge (PZC $=74.45 \mu \mathrm{g} / \mathrm{ml})$. The hydrophilic surfaces, scoured and bleached as well as DMDHEU-treated cotton fabrics, which have better accessibility obtained by fiber swelling and enlargement of the primary interfibrillar and/ or intrafibrillar places, show a similar adsorption of cationic surfactant N-CPC (PZC around $56 \mu \mathrm{g} / \mathrm{ml})$. On the other hand, hydrophobic surfaces (FC resin treated, F1 and F3) adsorb fewer cations having PZC around $45 \mu \mathrm{g} / \mathrm{ml}$.

The specific amount of surface charge obtained by the backtitration method confirmed the assumptions about the cotton fabric surface charge placed by the ZP and PZC. The raw cotton fabric has a highly negative surface charge of -2.45 $\mathrm{C} / \mathrm{g}$. Removal of noncellulosic impurities in the scouring and bleaching process increase the surface charge. Therefore, bleached cotton fabric shows a surface charge of $=-2.29 \mathrm{C} / \mathrm{g}$. Application of DMDHEU results in almost the same surface charge of $=-2.25 \mathrm{C} / \mathrm{g}$. Treatment with $\mathrm{FC}$ resin significantly reduced the charge $q(F 1)=-2.05 \mathrm{C} / \mathrm{g}$ and $q(F 3)=-1.98 \mathrm{C} / \mathrm{g}$.

When a drop of liquid is set on a solid surface, it creates a contact angle. Researching contact angles that different liquids form on textile material, its wettability and surface free energy can be characterized. The results of contact angle measurements on the cotton fabrics are given in Table 3. Surface free energies of cotton fabrics calculated from the results of contact-angle measurements according to Wu's and Owens-Wendt's models are presented in Table 4 and according to the acid-base model in Table 5.

From Table 3, it is evident that the contact angle could not be measured on highly hydrophilic surfaces. Results show that nonpolar liquid diiodomethane forms contact angles on raw and all finished fabrics, while polar liquids, water, and formamide, only the raw fabric and fabrics finished with water- oil-repellent agent that containing melamine and $\mathrm{FC}$ resin (F 1 and $\mathrm{F} 3$ ). On hydrophilic fabrics, scoured, bleached, and easy-care finished (F 2) water and formamide do not form contact angles, but they penetrate into its porous structure. The reason is the capillary sorption, which results in contact angles lower than $90^{\circ}$. The contact angle between fabric and formamide is lower than $20^{\circ}$ and could not be determined. The water- oil-repellent finishing

Table 3: Contact angle measured on FIBRO DAT 500/1100 (Fibro) instrument

\begin{tabular}{|c|c|c|c|}
\hline \multirow{2}{*}{ Fabric } & \multicolumn{3}{|c|}{ Contact angle [ ${ }^{\circ}$ ] } \\
\cline { 2 - 4 } & $\boldsymbol{\Theta}_{\text {WATER }}$ & $\boldsymbol{\Theta}_{\text {FORMAMIDE }}$ & $\boldsymbol{\Theta}_{\text {DIIODOMETHANE }}$ \\
\hline R & 142,1 & 123,5 & 93,2 \\
\hline ES & $/^{*}$ & $/$ & $/$ \\
\hline EB & $/^{*}$ & $/$ & $/$ \\
\hline B & $/^{*}$ & 121,2 & 107,6 \\
\hline F 1 & 126,2 & $/$ & 83,6 \\
\hline F 2 & $/$ & 120,4 & 103,0 \\
\hline F 3 & 126,7 & & $/$ \\
\hline
\end{tabular}

* Highly hydrophilic surfaces, contact angle could not be measured

Table 4: Surface free energy components according to Wu's and Owens-Wendt's models

\begin{tabular}{|c|c|c|c|c|c|c|}
\hline \multirow[b]{2}{*}{ Fabric } & \multicolumn{3}{|c|}{ Wu's model } & \multicolumn{3}{|c|}{ Owens-Wendt's model } \\
\hline & $\begin{array}{c}\mathrm{Y}^{d} \\
{\left[\mathrm{~mJ} / \mathrm{m}^{2}\right]}\end{array}$ & $\begin{array}{c}\mathrm{Y}^{p} \\
{\left[\mathrm{~mJ} / \mathrm{m}^{2}\right]}\end{array}$ & $\begin{array}{c}\mathrm{Y} \\
{\left[\mathrm{mJ} / \mathrm{m}^{2}\right]}\end{array}$ & $\begin{array}{c}\mathrm{Y}^{d} \\
{\left[\mathrm{~mJ} / \mathrm{m}^{2}\right]}\end{array}$ & $\begin{array}{c}\mathrm{V}^{p} \\
{\left[\mathrm{~mJ} / \mathrm{m}^{2}\right]}\end{array}$ & $\begin{array}{c}Y \\
{\left[\mathrm{~mJ} / \mathrm{m}^{2}\right]}\end{array}$ \\
\hline $\mathrm{R}$ & 16,57 & 0 & 16,57 & 10,14 & 1,22 & 11,36 \\
\hline ES & $1^{*}$ & I & I & $1^{*}$ & l & l \\
\hline Blab & $/^{*}$ & l & l & $/^{*}$ & I & I \\
\hline B & $/^{*}$ & l & l & $/^{*}$ & l & I \\
\hline F 1 & 10,47 & 0 & 10,47 & 5,20 & 0,23 & 5,43 \\
\hline F 2 & l & 1 & I & l & 1 & I \\
\hline F 3 & 11,98 & 0 & 11,98 & 6,41 & 0,07 & 6,48 \\
\hline
\end{tabular}

* Highly hydrophilic surfaces, contact angle could not be measured 
that contains FC resin, increase the contact angle. Water forms the highest contact angle in all finished cotton fabrics ( $F 1$ and $F$ 3), rather than formamide and diiodomethane. The components of surface free energy of cotton fabrics were calculated from the results of contact-angle measurements according to the acid-base model, and shown in Table 4, but only for hydrophobic fabrics (R, F 1, and F 3).

For the reason that this method is not appropriate for heterogeneous, porous, and mostly hydrophilic textiles, the Chibowski thin-layer wicking method for the surface free energy components determination was performed on hydrophilic surfaces (ES, $B_{\text {lab }}, B_{\text {ind }}, F$ 2) and compared to the acid-base model of the contact-angle method. The results of the liquid penetration rates into the hydrophilic cotton fabrics according to thin-layer wicking method by Chibowski et al. are presented in Figure 4. Figures 4a through 4d show the plots of the liquid penetration rate into enzymatic scoured $(E S)$, bleached $\left(B_{\text {lab }}\right.$ and $B_{\text {ind }}$ ), and finished ( $F 2$ ) fabrics. The Washburn equation is only valid if the squared penetrated distance, $x^{2}$, is a linear function of the time, $t$. Therefore, only those parts of plots are presented. According to the Washburn equation, the higher the penetration rate, the lower the slope of the plot.

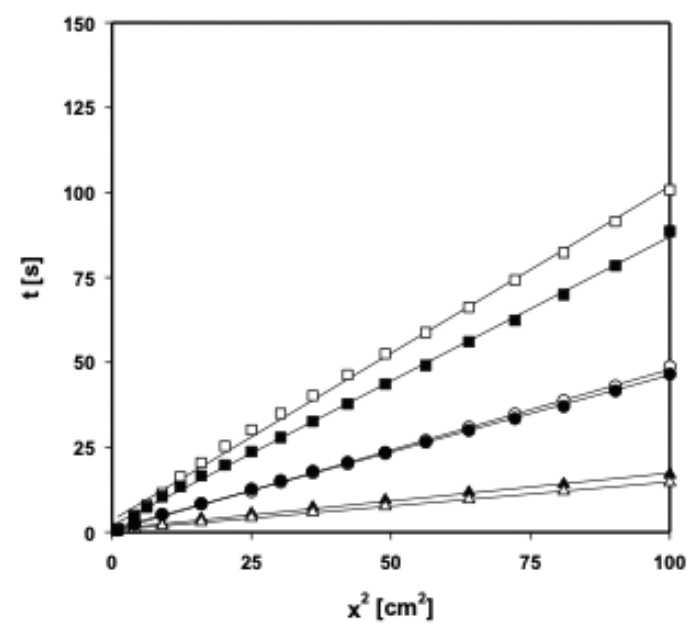

a.

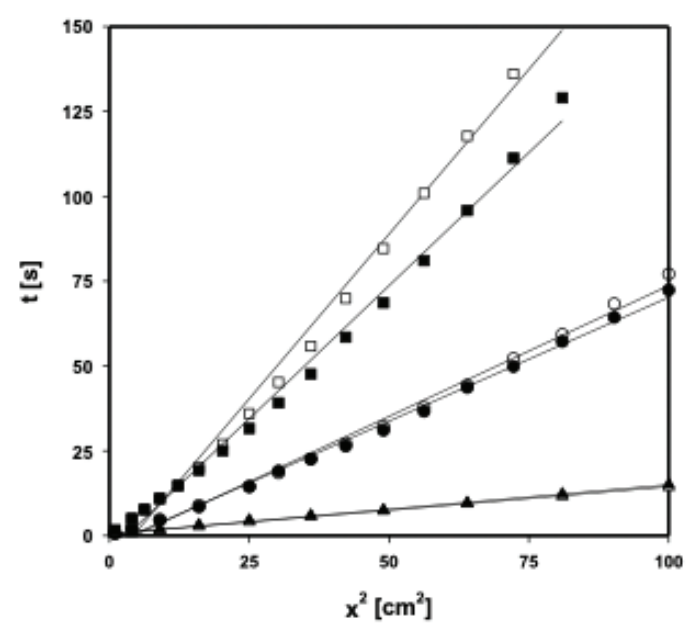

c.

Figure 4 Liquid penetration rates into fabrics: (a) ES, (b) EB (c) B and (d) F 2. Bare fabrics: - $\triangle$ - n-heptane, -O- water, - $\square$ - formamid; precontacted fabrics with liquid saturated vapour: $-\mathbf{\Delta}$ - $n$-heptane, $-\boldsymbol{-}$ - water, $-\boldsymbol{-}-$ - formamid
It can be seen from Figure 4 that the liquid penetration rate depends on the liquid properties as well as on the fabric preparation. The highest penetration rate is obtained for n-heptane and the lowest one for formamide regardless of the fabric preparation. It is also evident that the liquid wicking velocity into the bare fabric differs from that obtained for the saturated one. Since the pretreated cotton fabrics ES, $B_{\text {lab }}$, and $B_{\text {ind }}$ are highly wettable by all studied liquids, $n$-heptane is the only wicking liquid in the case of the hydrophobic fabric $R$ and water-oil repellent finished fabrics $F 1$ and $F 3$. Therefore, the liquid penetration rate into these fabrics is not presented in Figure 1, and the surface free energy could not be calculated for these samples. Comparing the results of surface free energy, it is evident that the thin-layer wicking method is more appropriate for hydrophilic textiles because there is no need to measure the contact angle. The contact angle is almost impossible to measure on hydrophilic surfaces, but for hydrophobic surfaces, it is irreplaceable. From the results of surface free energy according to the acid-base model, it can be seen that the results for the surface free energy are close to the Chibowski thin-layer wicking (TLW) results. Therefore, the cumulative results for these two methods are presented in Table 5.

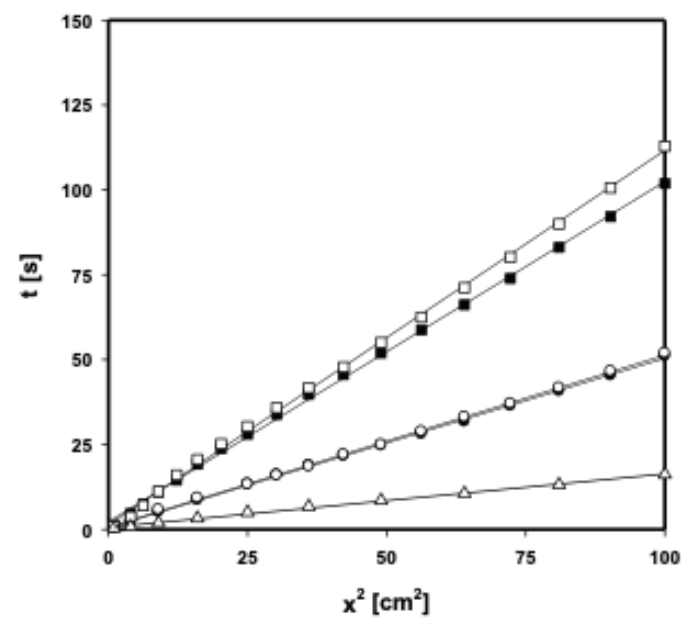

b.

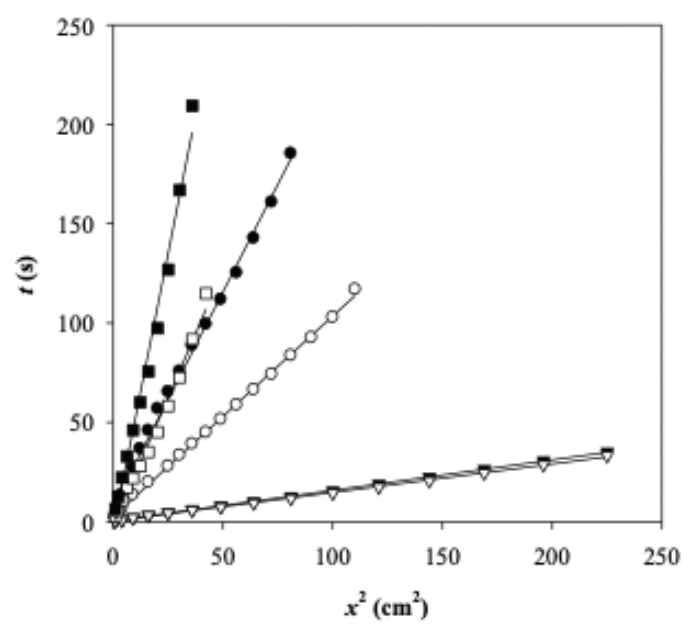

d. 
Table 5: Surface free energy components of the pretreated and finished cotton fabrics - Thin-layer wicking method according to Chibowski et al. $\left(R_{T L W}, B_{T L W}, F 2_{T L W}\right)$ and contact angle method-acid-base model $\left(R_{A B}, F 1_{A B}, F 3_{A B}\right)$

\begin{tabular}{|c|c|c|c|c|c|c|}
\hline Fabric & $\begin{array}{c}\mathbf{Y}_{\mathrm{s}}^{\mathrm{LW}} \\
{\left[\mathrm{mJ} / \mathrm{m}^{2}\right]}\end{array}$ & $\begin{array}{c}\mathrm{v}_{\mathrm{s}}^{+} \\
{\left[\mathrm{mJ} / \mathrm{m}^{2}\right]}\end{array}$ & $\begin{array}{c}\mathrm{Y}_{\mathrm{s}}^{\cdot} \\
{\left[\mathrm{mJ} / \mathrm{m}^{2}\right]}\end{array}$ & $\begin{array}{c}\mathrm{V}_{\mathrm{s}}^{\mathrm{AB}} \\
{\left[\mathrm{mJ} / \mathrm{m}^{2}\right]}\end{array}$ & $\begin{array}{c}\mathbf{Y}_{\mathrm{s}}^{\text {tot }} \\
{\left[\mathrm{mJ} / \mathrm{m}^{2}\right]}\end{array}$ & $\underset{\left[\mathrm{mJ} / \mathrm{m}^{2}\right]}{\mathbf{W}_{\mathbf{A}}}$ \\
\hline $\mathrm{R}_{\mathrm{AB}}$ & 45,26 & 0 & 0 & 0 & 45,26 & 62,82 \\
\hline $\mathrm{R}_{\mathrm{TLW}}$ & 44,72 & 0 & 0 & 0 & 44,72 & 62,45 \\
\hline $\mathrm{ES}_{\mathrm{TLW}}$ & 49,53 & 0,02 & 62,35 & 3,48 & 53,01 & 146,90 \\
\hline $\mathrm{EB}_{\mathrm{TLW}}$ & 47,77 & 0,08 & 59,52 & 4,47 & 52,24 & 145,31 \\
\hline $\mathrm{B}_{\mathrm{TLW}}$ & 45,68 & 0,09 & 61,05 & 4,68 & 50,36 & 145,06 \\
\hline $\mathrm{F} 1_{\mathrm{AB}}$ & 6,18 & 0,28 & 1,40 & 1,25 & 7,43 & 40,51 \\
\hline $\mathrm{F} 2_{\mathrm{TLW}}$ & 47,36 & 1,51 & 51,28 & 17,63 & 64,99 & 149,00 \\
\hline $\mathrm{F} 3_{\mathrm{AB}}$ & 7,63 & 0,52 & 1,14 & 1,54 & 9,17 & 43,86 \\
\hline
\end{tabular}

From the results of the components of surface free energies calculated according to acid-base model and thin-layer wicking shown in Table 5, it is evident that all studied fabrics are negatively charged due to the presence of carboxyl and hydroxyl groups, previously suggested by electrokinetic phenomena. The raw cotton fabric (R) is nonpolar, having $V_{S}{ }_{S}^{L W}$ equals to its total surface free energy, $V_{S}{ }^{\text {TOT }}$, no matter which model was applied for surface free energy calculation. Since scouring and bleaching processes enhance the number of available and causes formation of new surface groups, the pretreatment of cotton fabrics results in the high increase of the $\gamma_{S}{ }^{-}$value, but it does not have a significant effect on the increase of $\mathrm{Y}_{S}{ }^{+}$. This suggests that the pretreated cotton fabrics can be described as monopolar surfaces of strong electron donor capacity. These results are in good agreement with those of ZP and specific surface charge, since carboxyl and hydroxyl groups are strong electron donors. The water- oil-repellent agent $(F 1, F 3)$ reduces wettability of cotton fabrics. This is evident from the values of surface free energy, which in the case of pretreated bleached fabric (B) is $50.36 \mathrm{~mJ} / \mathrm{m}^{2}$, while in finishing $(F 1, F 3)$ reduced to values less than $10 \mathrm{~mJ} / \mathrm{m}^{2}$. These finishes significantly reduced the electron donor capacity. On the other hand, the easy-care finishing ( $F$ 2) results is $\mathrm{Y}_{S}^{+}$increment, while the $\mathrm{Y}_{S}^{-}$value remains high, more than $51 \mathrm{~mJ} / \mathrm{m}^{2}$. Because of crosslinking with DMDHEU, its electron acceptor capacity gets higher. This means that the incorporation of DMDHEU into the cellulose structure did not essentially change its surface properties, but that it remained a monopolar solid with a strongly expressed electron donor component, having work of adhesion $\left(W_{A}\right)$ is very high as for the pretreated fabrics $W_{A}=145 \mathrm{~mJ} / \mathrm{m}^{2}$. Based on the results, the agent for easy-care finishing that diffuses into the amorphous areas of cellulose fibers does not substantially alter the surface of the cotton fabric. The fabric remains polar having wettability as untreated (in this case bleached) cotton fabric. This shows that the strong reduction of surface free energy, achieved by applying a finishing $\mathrm{F} 1$ and $\mathrm{F} 3$, results in the presence an oil-repellent FC finishing agent in the polymer and not in the presence of DMDHEU. This was expected, since the FC polymer, which includes a perfluorinated hydrocarbon group in its secondary structure, is characterized by extremely low surface tension and high stability. FC polymer film, formed on the surface of cotton fabrics in the stage of condensation, overshadows the functional hydroxyl groups of cellulose fibers and hydrophilic polar surface changes in the high water- oilrepellent and nonpolar surfaces. The results of $\mathrm{W}_{\mathrm{A}}$ confirm that. Fabrics finished with $\mathrm{FC}$ resin have significantly lower work of adhesion, $\mathrm{W}_{\mathrm{A}}<40 \mathrm{~mJ} / \mathrm{m}^{2}$.

\section{CONCLUSIONS}

Pretreatment and finishing of cotton fabrics cause the modification of the textile surface properties resulting in a great change of its interface phenomena-ZP, surface charge, and surface free energy. All presented fabrics are negatively charged, mostly due to the presence of carboxyl and hydroxyl groups.

In the case of raw cotton, hydroxyl and carboxyl groups existed, but they were covered by noncellulose compounds (proteins, oils, waxes, pectin, carbohydrates and inorganic materials, etc.). Its nonpolar surface with $\mathrm{V}_{S}{ }^{\mathrm{LW}}$ equals to its total surface free energy, $Y_{S}{ }^{\text {TOT }}$.

The scouring and bleaching processes result in degradation and removal of practically all noncellulose compounds. It causes interfibrillar swelling, and the active surface is increased, which is observed by the decreased ZP and in the increase of the $Y_{S}$ value, but it does not have a significant effect on the increase of $\mathrm{Y}_{\mathrm{S}}{ }^{+}$. This suggests that the pretreated cotton fabrics can be described as having monopolar surfaces of strong electron donor capacity.

The water- oil-repellent agent reduces the wettability of cotton fabrics. The FC polymer film overshadows the functional hydroxyl groups of cellulose fibers and hydrophilic polar surface changes into the nonpolar surface. The total surface free energy of these fabrics is $Y_{S}{ }^{\text {TOT }}<10 \mathrm{~mJ} / \mathrm{m}^{2}$. On the other hand, the easy-care finishing, because of crosslinking with DMDHEU, results in $Y_{s}{ }^{+}$increment, while the $\gamma_{s}{ }^{-}$value remains high and does not substantially alter the surface of cotton fabric. 
It is to point out that the thin-layer wicking method for determination the surface free energy is more appropriate for hydrophilic textiles because there is no need for contact-angle determination. Contact angle is almost impossible to measure on hydrophilic surfaces, but for hydrophobic surfaces, it is irreplaceable.

\section{ACKNOWLEDGMENTS}

Authors acknowledge Ministry of Science, Education and Sports of Republic of Croatia, and Slovenian Research Agency for financial support to the Project entitled "Surface free energy of pretreated and finished textiles" in Slovenia-Croatia cooperation in science and technology.

\section{REFERENCES}

[1] Jacobasch HJ. Oberflächenchemie faserbildender polymerer, Akadenie Verlag, Berlin 1984

[2] Jacobasch HJ and Schurz J. Characterization of Polymer Surfaces by means of Electrokinetic Measurements. Progr Colloid \& Polymer Sci 1988; 77: 40-48.

[3] Stana-Kleinschek K, Strand S and Ribitsch V. Surface Characterization and Adsorption Abilities of Cellulose Fibers, Polymer Engineering and Science 1999; 39: 14121424.

[4] Grancarić AM, Pušić T, Soljačić I and Bišćan J. Electrokinetic Behaviour of Textile Fibers, Polimeri 2002; 23: 121-128.

[5] Grancarić AM, Tarbuk A and Pušić T. Electrokinetic Properties of Textile Fabrics, Coloration Technology 2005; 121: 221-227.

[6] Grancarić AM, Chibowski E, and Tarbuk A. Surface Free Energy of Textiles, Tekstil 2008; 57: 29-39.

[7] Grancarić AM, Chibowski E, Pušić T, Soljačić I and Plantić Lj. Surface Free Energy of Conventional and Enzymatically Scoured Cotton Fabrics. In: Book of proceedings of the $1^{\text {st }}$ ITC\&DC, (Ed. Dragcevic Z), Dubrovnik, Croatia, 5-8 Oct 2002, pp. 267-273, Zagreb: Faculty of Textile Technology, University of Zagreb.

[8] Bišćan J. Electrokinetic Data: Approaches, Interpretations and Application, Croatica Chemica Acta 2007; 80: 357365.

[9] Luxbacher T. Electrokinetic properties of natural fibres, In: Handbook of Natural Fibres: Processing and Applications, (ed. R.M. Kozłowski), (2012), pp. 185-216, Woodhead Publishing Series in Textiles, Elsevier.

[10] Stana-Kleinschek $K$ and Ribitsch V. Electrokinetic properties of Processed Cellulose Fibers, Colloids and Surfaces, A: Physicochemical and Engineering Aspects 1998; 140: 127-138.

[11] Grancarić AM, Ristić N, Tarbuk A and Ristić I. Electrokinetic Phenomena of Cationized Cotton and its Dyeability with Reactive Dyes. Fibres \& Textiles in Eastern Europe 2013; 21: 106-110.

[12] Tarbuk A, Grancarić AM and Leskovac M. Novel cotton cellulose by cationisation during mercerisation - Part 2: Interface phenomena; Cellulose 2014; 21: 2089-2099
[13] Pušić T, Grancarić AM, Tarbuk A, Šauperl O and Soljačić I. Adsorption and Desorption of lonic Surfactants, Tenside, surfactants, detergents 2010; 47: 173-178.

[14] Pušić T, Tarbuk A and Dekanić T. Bio-innovation in cotton scouring - acid and neutral pectinases. Fibres \& Textiles in Eastern Europe 2015; 23: 98-103.

[15] Peršin Z, Stana-Kleinschek K, Sfiligoj-Smoje M, Kreže $T$ and Ribitsch V. Determining the Surface Free Energy of Cellulose Materials with the Power Contact Angle Measurement. Textile Research Journal 2004; 74: 55-62.

[16] Černe $L$ and Simončič B. Influence of repellent finishing on the surface free energy of cellulosic textile substrates, Text Res J 2004; 74: 426-432.

[17] Černe L, Simončič $B$ and Željko $M$. The influence of repellent coatings on surface free energy of glass plate and cotton fabric. Applied Surface Science 2008; 254: 6467-6477.

[18] Simončič B and Černe L. Influence of Different parameters on the Surface Free Energy of Finished Cotton Fabrics, Tekstilec 2004; 47: 6-12.

[19] Simončič B, Černe L, Tomšič B and Orel B. Surface properties of cellulose modified by imidazolidinone. Cellulose 2008; 15: 47-58.

[20] Tarbuk A, Grancarić AM and Leskovac M. Novel cotton cellulose by cationisation during the mercerisation process - Part 1: Chemical and morphological changes. Cellulose 2014; 21: 2167-2179.

[21] Fowkes FM and Mostafa MA. Acid-Base Interactions in Polymer Adsorption. Ind. Eng. Chem. Prod. Res. Dev. 1978, 17: 3-7.

[22] Good, R. J.: Contact Angle, Wetting and Adhesion - a critical review. In Contact Angle Wettability and Adhesion (Mittal, K. L., Ed.), VSP, Utrecht, The Netherlands, (1993), 3-36.

[23] van Oss, C. J.: Interfacial Forces in Aqueous Media, Marcel Dekker Inc., New York 1994.

[24] Owens DK and Wendt RC. Estimation of the Surface Free Energy of Polymers, J. Appl.Polym. Sci. 1969; 13: 17411747.

[25] Wu S. Polar and Nonpolar Interactions in Adhesion, J. Adhesion 1973; 5: 9-55.

[26] Ženkiewicz M. Methods for the Calculation of Surface Free Energy of Solids. Journal of Achivements in Materials and Manufacturing Engieneering 2007; 24: 137-145.

[27] Chibowski $E$ and Gonzalez-Caballero F. Theory and practice of thin layer wicking. Langmuir 1993; 9: 330-340.

[28] Chibowski E. Thin layer wicking - Methods for the determination of acid-base energies of interaction, AcidBase Interaction: Relevance to Adhesion Science and Technology 2000; 2: 419-437.

[29] Oh SY, Yoo DI, Shin Y and Seo G. FTIR Analysis of Cellulose Treated with Sodium Hydroxide and Carbon Dioxide. Carbohydrate Research 2005; 340: 417-428.

[30] Church JS and Evans DJ. The Quantitative Analysis of Fluorocarbon Polymer Finishes on Wool by FT-IR Spectroscopy, J. Appl. Polym. Sci. 1995; 57: 1585-1594.

[31] Merline DJ, Vukusic $S$ and Abdala AA. Melamine formaldehyde: curing studies and reaction mechanis. Polymer Journal 2012; 45: 413-419. 